\title{
Experimental Study on Behavior of Shear Connectors Embedded in Steel-Reinforced Concrete Joints
}

\author{
R.Nakamori ${ }^{\mathrm{a} *}$, Y.Kageyama ${ }^{\mathrm{b}}$, and N. Baba ${ }^{\mathrm{c}}$ \\ ${ }^{a}$ Graduate School, Osaka Institute of Technology, Osaka 535-8585, Japan \\ ${ }^{\mathrm{b}}$ TAISEI CORPORATION, Osaka 542-0081, Japan \\ 'Professor, Department of Architecture, Faculty of Engineering, Osaka Institute of Technology, Osaka 535- \\ 8585, Japan \\ *corresponding author, e-mail address:m1m17208@st.oit.ac.jp
}

\begin{abstract}
This paper presents an experimental study on the behavior of shear connectors embedded in steel-reinforced concrete joints.

In steel-reinforced concrete joints, the shear connectors are commonly used to transfer longitudinal shear forces across the steel-concrete interface. Further, in Japan, some studies in recently have also been undertaken to apply perfobond rib shear connector (PBL), which is a type of shear connectors developed in civil engineering, to the steel-reinforced concrete joints in building structures.
\end{abstract}

To clarify the influence of the arrangement methods of headed studs and PBLs to reinforced concrete member on the joints, T-shaped subassembrages were tested under the monotonic tensil loading. This experiment is constituted of the following;

Exp. I: Bond strength across the steel-concrete interface.

Exp. II: Arrangement methods of these shear connectors to reinforced concrete member.

The following can be drawn from the test results

1) The experimental values of the average maximum and residual bond strength are 0.230 0.280 and $0.15-0.18 \mathrm{~N} / \mathrm{mm}^{2}$, respectively.

2) When the distance of between the upper surface of the reinforced concrete member from the first layer for headed studs are small, the failure mode of the specimens is similar to a concrete-cone type failure.

3) In the case that the total number of headed studs or the hole provided to PBL is the same, the maximum load of the specimen with the parallel arrangement is larger than that of when shear connecters are vertically arranged.

4) The shear strength of headed studs in the joints embedded the steel member in the reinforced concrete member is estimated by superposing the average residual bond strength across the steel-concrete interface.

Keywords: headed stud; perfobond rib shear connector; punching shear failure; share strength; average residual bond strength

\section{Introduction}

In steel-reinforced concrete joints, the shear connectors are commonly used to transfer longitudinal shear forces across the steelconcrete interface. As such a typical joint, there is composite beams with headed studs. On the other hand, there are some studies to investigate the behavior of the headed studs embedded in the steel-reinforced concrete joints of various types. Further, in Japan, some studies in recently have also been undertaken to apply perfobond rib shear connector (PBL), which is a type of shear connectors developed in civil engineering, to the steel-reinforced concrete joints in building structures.

Fig. 1. shows the previous studies which are classified into type of the steel-reinforced concrete joints used these shear connectors in architecture.

The objective of this study is to clarify experimentally the following about the behavior 
of headed studs and PBLs arranged to the joint type shown in Fig. 1 (b and c).

(Exp. I) Bond strength across the steel-concrete interface.

(Exp. II) Arrangement methods of these shear connectors to reinforced concrete member.

\section{Experiment}

To clarify the influence of the arrangement methods of headed studs and PBLs to reinforced concrete member on the joints, T-shaped subassembrages were tested. The following experimental variables are shown in Table 1.

(Exp. I) The transverse reinforcement ratio around the shape steel tube embedded in the reinforced concrete member.

(Exp. II) The type and arrangement of the shear connectors.

The overall dimensions of the specimen, the cross sections and reinforcement details are shown in Fig. 2. All specimens have square steel tube of a cross-section of one side length of
$150 \mathrm{~mm}$, and the reinforced concrete member with the width of $350 \mathrm{~mm}$ and the depth of $500 \mathrm{~mm}$. The shear connectors are ${ }_{s t} d=\phi 13$ of headed studs and PBLs consist of the thickness $9 \mathrm{~mm}$ of the steel plate with a hole of $35 \mathrm{~mm}$ diameter. The height ${ }_{s t} L$ of headed studs are 40 , 52.5 or $80 \mathrm{~mm}\left({ }_{s t} L /{ }_{s t} d=3.08,4.04\right.$ or 6.15$)$.

In the specimens with headed studs (Specimen No.4-12), the distance ${ }_{s t} H(=40,52.5$ or $80 \mathrm{~mm}$ ) from the upper surface of the reinforced concrete member to the first layer for headed studs and the pitch lengths of headed studs ${ }_{s t} p(=80$ or $112.5 \mathrm{~mm})$ are combined. In the case of Specimens No.11 and 12 with headed studs arranged in parallel, the gauge lengths ${ }_{s t} g$ of headed studs are $80 \mathrm{~mm}$. Specimen No.13 and 14 with PBL have one or parallel sheets of the steel plates on one side of the square steel tube and have the same pitch and gauge lengths as Specimens No.9-12. Further, the specimens for Exp. I (Specimens No.1-3) do not have the shear connecters. The mechanical properties of the materials are listed in Table 2.

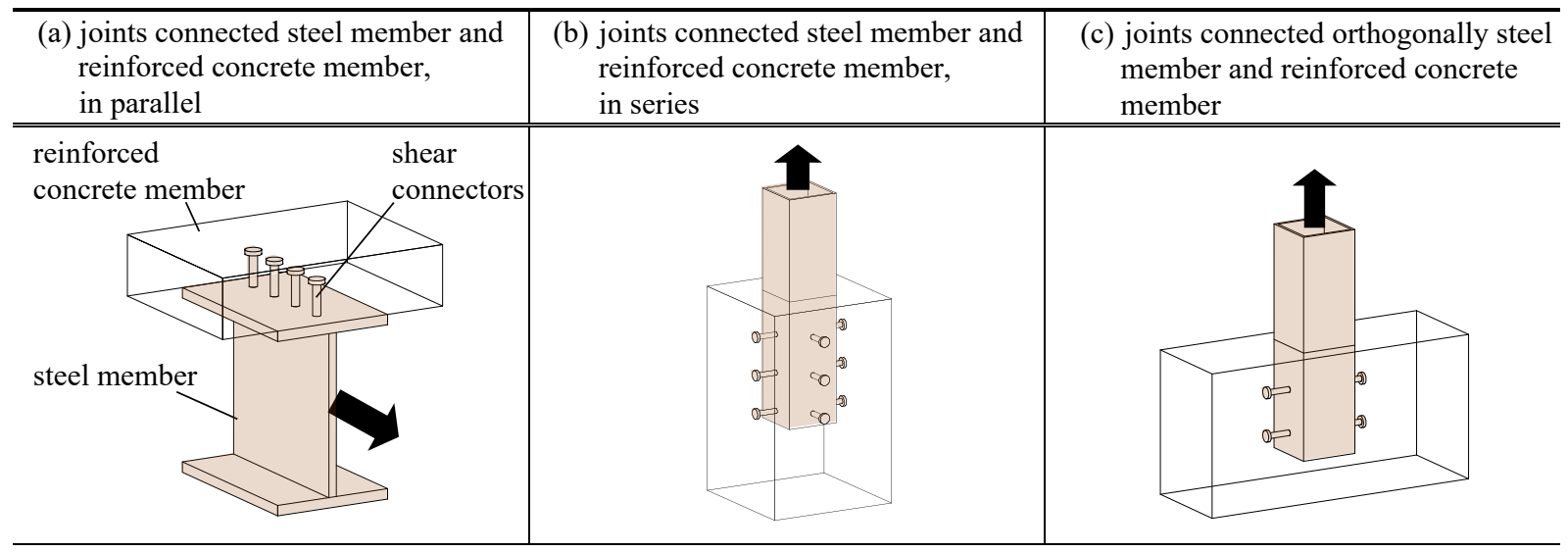

Fig. 1. Type of the steel-reinforced concrete joints

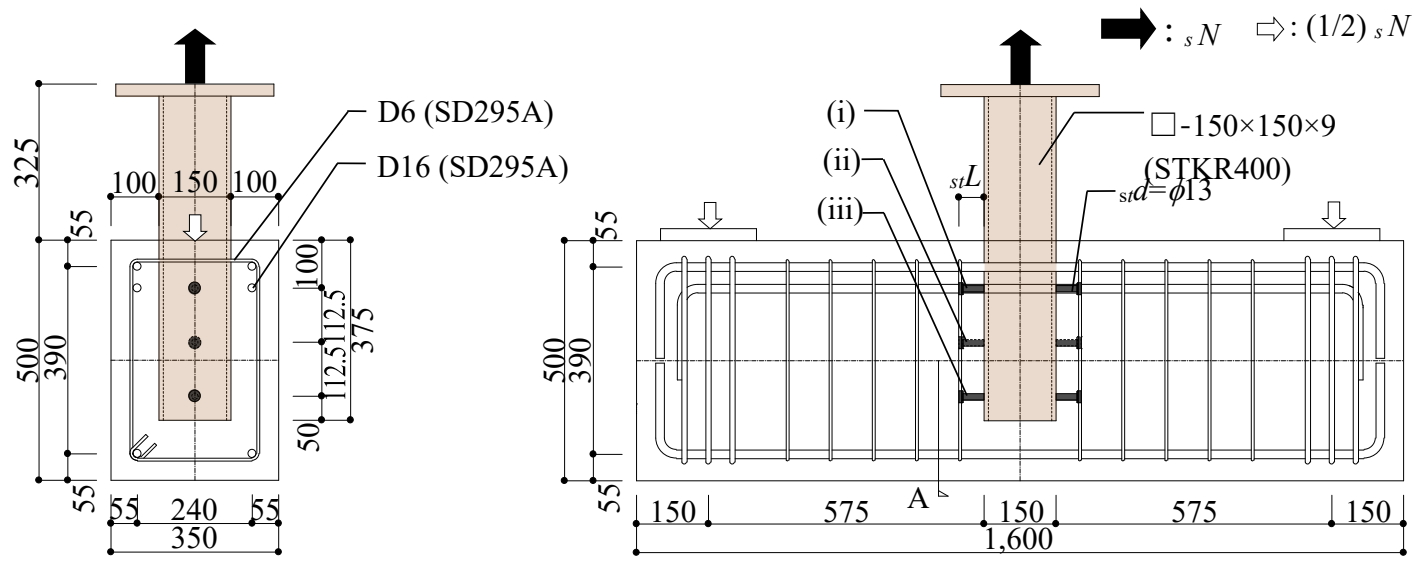

Fig. 2. Details of specimens 


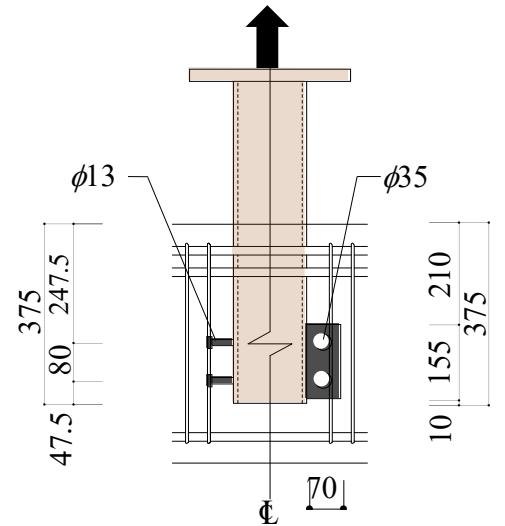

Fig. 3. Details of specimens (Specimen No.9-14)

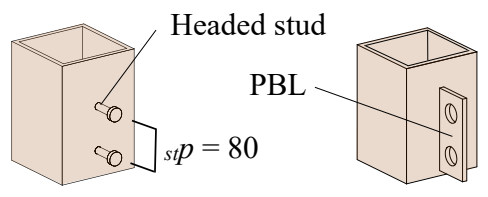

(a) Vertical arrangment
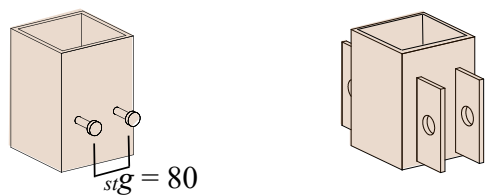

(b) Parallel arrangment

Fig. 4. Arrangement of shear connectors

Test set-up is shown in Fig. 5. The monotonic tensile loading was applied at the end of the square steel tube.

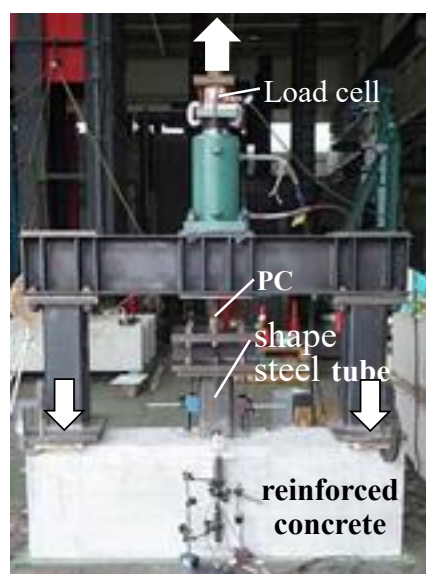

Fig. 5. Test set-up
Table 1. Mechanical properties of Materials

\begin{tabular}{|c|c|c|c|c|}
\hline $\begin{array}{c}\text { Specimen } \\
\text { No. }\end{array}$ & Type & $\begin{array}{c}\text { height of stud } \\
\text { (hole size of PBL) }\end{array}$ & $\begin{array}{l}p_{w} \\
(\%)\end{array}$ & $\begin{array}{c}\text { arrengement methods } \\
\text { of shear connecters }\end{array}$ \\
\hline No.1 & \multirow{3}{*}{ bond } & \multirow{3}{*}{ - } & 0 & \multirow{3}{*}{ - } \\
\hline No. 2 & & & \multirow{7}{*}{0.2} & \\
\hline No.3 & & & & \\
\hline No.4 & \multirow{9}{*}{$\begin{array}{c}\text { headed } \\
\text { stud }\end{array}$} & 40 & & \multirow{3}{*}{ (i)and(iii) (Fig. 2.) } \\
\hline No.5 & & 52.5 & & \\
\hline No.6 & & \multirow{3}{*}{80} & & \\
\hline No.7 & & & & (i)and(ii) (Fig. 2.) \\
\hline No. 8 & & & & (ii) and(iii) (Fig. 2.) \\
\hline No.9 & & 52.5 & \multirow{6}{*}{0.4} & VEFFig 4 (a) \\
\hline No. 10 & & 80 & & VE(Fig. 4 (a).) \\
\hline No.11 & & 52.5 & & PA (Fin 4 (b) \\
\hline No.12 & & 80 & & PA(FIg. $4(0))$. \\
\hline No.13 & \multirow{2}{*}{ PBL } & \multirow{2}{*}{35} & & VE(Fig. 4 (a).) \\
\hline No.14 & & & & PA(Fig. 4 (b).) \\
\hline
\end{tabular}

\section{Results and discussions}

\subsection{Bond strength between surface of shape steel tube and concrete.}

The relationships between the average bondstrength and the slippage of the shape steel tube are shown in Fig. 6. The vertical axis represents the average bond strength across the steel-concrete interface, and the horizontal axis gives the slippage of the shape steel tube to the reinforced concrete member. The maximum average bond strength is based on the proposed formula (1) [Nishimura et.al., 2001].

$$
\tau_{\max }=0.597 \sigma_{c}+5.30 \quad\left(\mathrm{kgf} / \mathrm{cm}^{2}\right)
$$

where, $\sigma_{c}$ is Compressive stress applied to flat steel surface (this test is $\sigma_{c}=0$ ).

The experimental values of the average maximum bond strength $\tau_{b \max }$ were $0.230-0.280$ $\mathrm{N} / \mathrm{mm}^{2}$, and the bond strength of the shape steel tube is about half calculated from the formula (1) for one sheet of the steel plate. On the other hand, the average residual bond strength $\tau_{b r}$ were 0.15 $0.18 \mathrm{~N} / \mathrm{mm}^{2}$.

From this test results, the maximum and average residual strength are not almost influenced by the transverse reinforcement ratio around the shape steel tube embedded in the reinforced concrete member, but they are influenced by concrete compressive strength $\sigma_{B}$. In addition, since the shear resistance forces of the shear connector were achieved after reaching the maximum bond strength, the bond strength of shape steel tube should be applied the average 


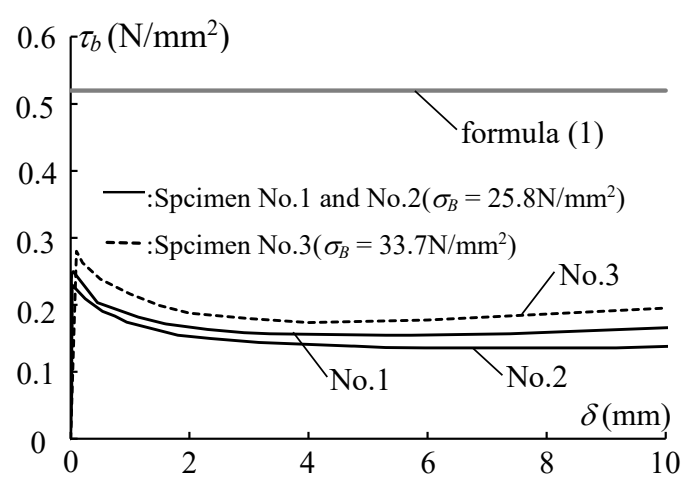

Fig. 6. The relationships between the average bond strength and the slippage of the shape steel tube (Exp. I)

residual strength. Further, the slippage with the average maximum bond strength is about 0.01 $\mathrm{mm}$.

\subsection{The type and arrangement of the shear connectors}

The crack observations after test are shown in Fig. 7. When the distance ${ }_{s t} H$ of between the upper surface of the reinforced concrete member from the first layer for headed studs were small, the failure mode of the specimens was similar to a concrete-cone type failure. Therefore, the punching shear failure of concrete on the upper surface of the reinforced concrete member by the outward thrust force at headed studs was observed remarkably. However, the punching shear failure was suppressed in specimens with the large distance ${ }_{s t} H$. On the other hand, the specimens with PBL were not observed the significant punching shear failure of concrete in comparison with the specimens having the headed studs.

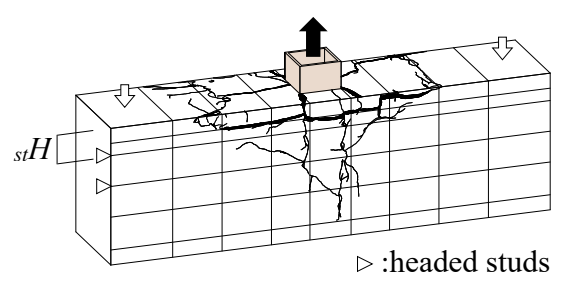

Specimen No.7

(a) Headed studs with small distance ${ }_{s t} H$

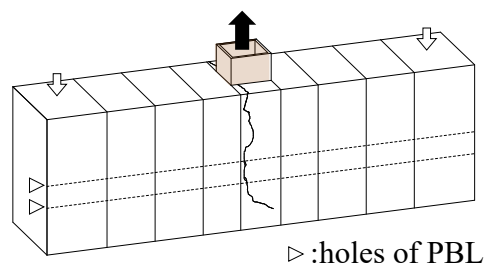

Specimen No.13

(c) PBL with one sheet of steel plate
The load-displacement relationships of each specimen are shown in Fig. 8. The vertical axis represents the tensile force ${ }_{n} N$ loaded on the shape steel tube. The horizontal axis gives the slippage $\delta$ of the shape steel tube until $d$ is $15 \mathrm{~mm}$. The following outlines the influence of the experimental variables on the shear strength of headed studs.

(a) Height of headed studs (Fig. 8 (a))

There is no influence of the headed stud heights on the shear strength.

(b) Headed studs with vertical arrangement

(Fig. 8 (b))

Since the maximum load of each specimen does not differ, the shear strength of headed studs of when the distance ${ }_{s t} H$ were small is determined based on the punching shear failure of concrete. However, since Specimen No. 8 with the large distance ${ }_{s t} H$ is not observed the significant punching shear failure of concrete, the maximum load is larger than the other specimens.

(c) Headed studs with parallel arrangement

(Fig. 8 (c))

In the case that the total number of headed studs is the same, the maximum load of the specimen with the parallel arrangement is larger than that of when headed studs is vertically arranged

(d) Arrangement of PBL (Fig. 8 (d))

In the case that the total number of the hole provided to PBL is the same, the maximum load of the specimens with PBL arranged in parallel to the surface of the shape steel tube is larger than that of when PBL is one sheet of steel plate.

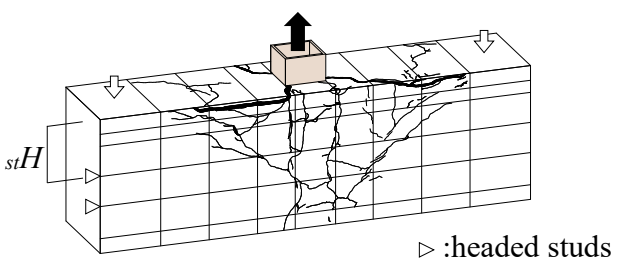

Specimen No.8

(b) Headed studs with large distance ${ }_{s t} H$

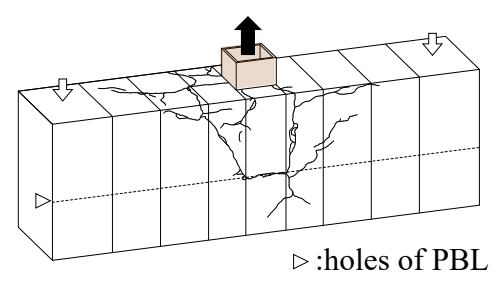

Specimen No.14

(d) PBL with parallel sheets of steel plate

Fig. 7. Crack observation after test 


\section{The shear resistance of headed studs}

Fig. 9. shows the axial strain distribution of the transverse reinforcement around the shape steel tube embedded in the reinforced concrete member at maximum load. The tensil strain of the transverse reinforcement at the point $\mathrm{A}$ shown in Fig. 9 reaches yield strain. However, the tensil strain except point A are extremely small.

Fig. 10. shows a resistance mechanism with the punching shear failure of concrete based on these test results. The angle of the diagonal cracking similar to a concrete-cone type failure corresponds the angles ${ }_{s t} \theta$ shown in Fig. 7. where, ${ }_{s t} \theta$ is the angle formed by the distance ${ }_{s t} H$

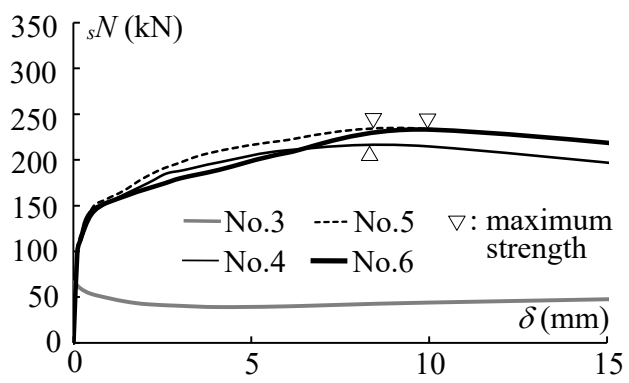

(a) Height of headed studs

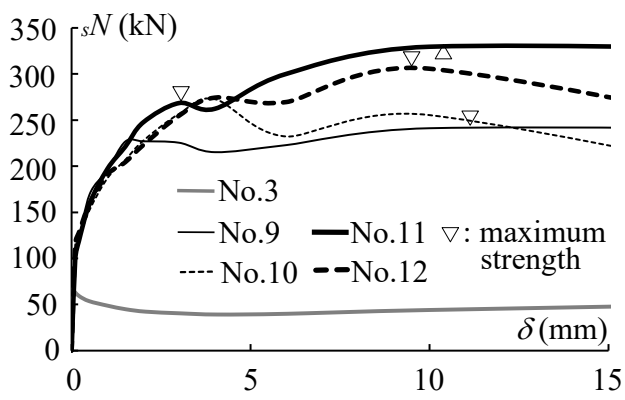

(c) Headed studs with parallel arrangement from the upper surface of the reinforced concrete member to the first layer for headed studs and the corner main reinforcement bars arranged in the cross-section of reinforcement concrete member. From this result, it is assumed that the punching shear strength of concrete is capable of estimating based on a strength evaluation for the concrete-cone type failure. Therefore, the punching shear strength is calculated on formula (2)-(5). Further, the effective horizontal projection length of the concrete is limited by the angle ${ }_{s t} \theta=45$ degrees.

$$
{ }_{s t} Q=0.313_{s t} A_{c} \sqrt{\sigma_{B}}
$$

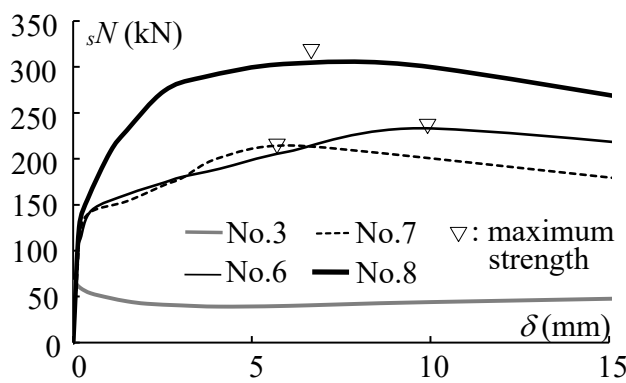

(b) Headed studs with vertical arrangement

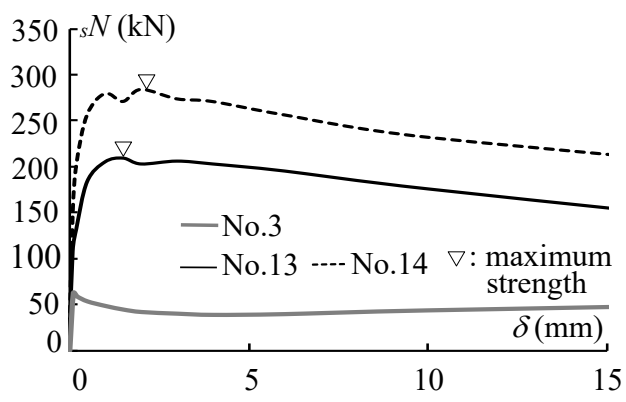

(d) Arrangement of PBL

Fig. 8. The load-displacement relationships (Exp. II)

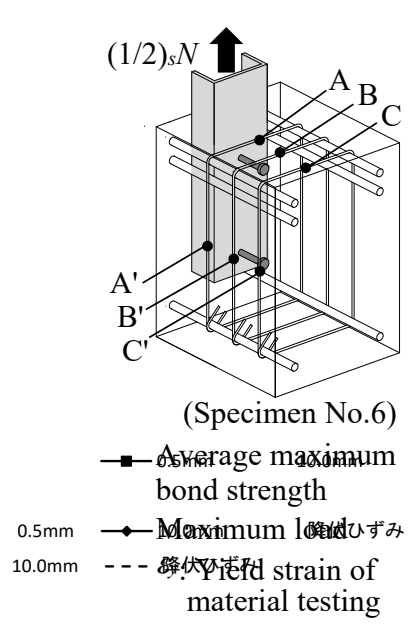

Fig. 9. Axial strain distribution of transverse reinforcement

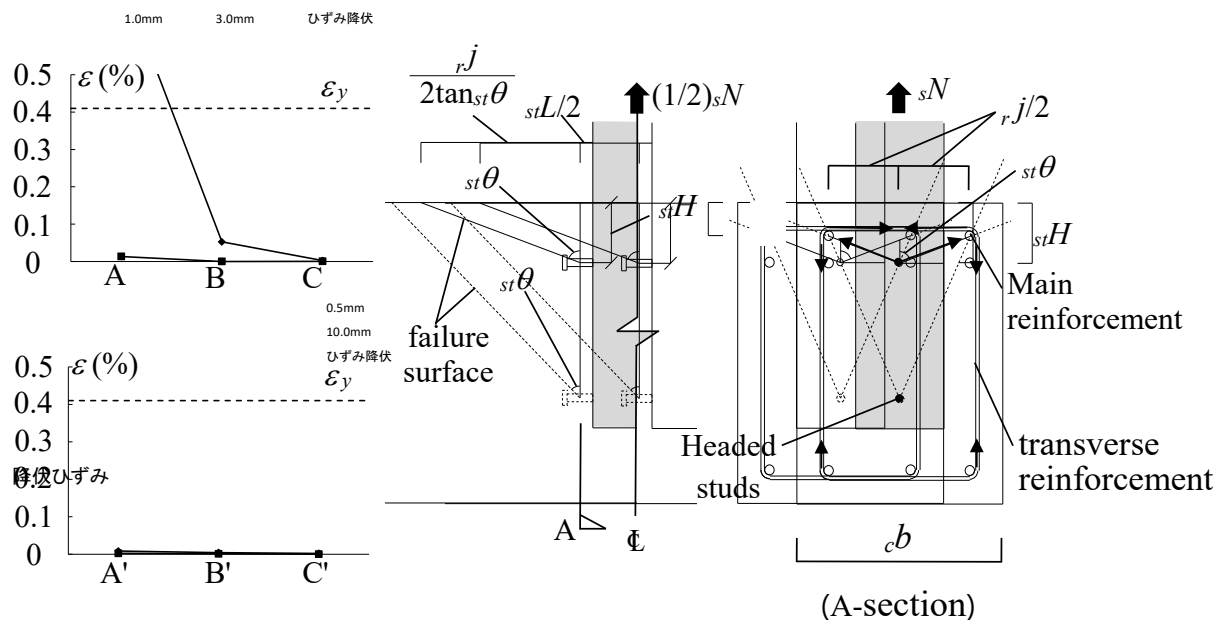

Fig. 10. Figure model of concrete 


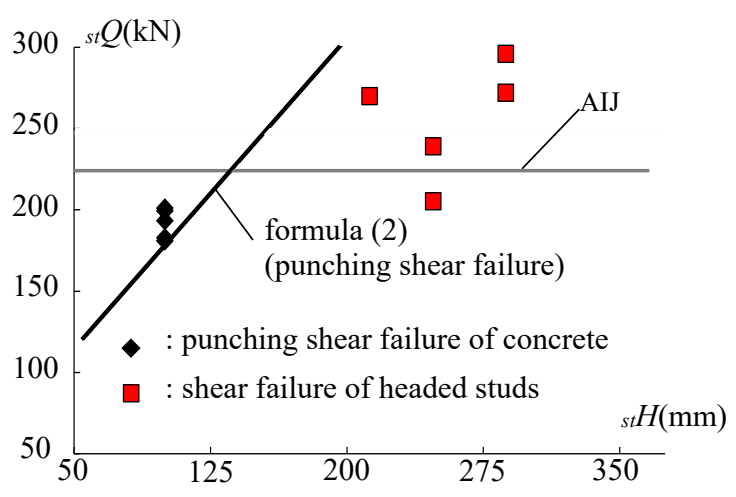

Fig. 11. The comparison of the predictions with test results

$$
\begin{gathered}
{ }_{s t} A_{c}={ }_{c} b \times{ }_{e} h \\
{ }_{e} h={ }_{s t} H+{ }_{s t} L / 2 \\
{ }_{e} h=\frac{{ }_{r} j}{2 \tan _{s t} \theta}+{ }_{s t} L / 2 \quad{ }_{s t} \theta>45 \mathrm{deg} .
\end{gathered}
$$

where,

${ }_{s t} A_{c}$ : effective horizontal projecting area of reinforced concrete member

${ }_{e} h$ : effective horizonal length

$c b$ : width of reinforced concrete member

${ }_{r} j$ : distance between main reinforcement bars

The comparison of the predictions with test results is shown in Fig. 11. The vertical axis represents the total shear strength ${ }_{s t} Q$ of headed studs. The horizontal axis gives the distance ${ }_{s t} H$. where, ${ }_{s t} Q$ is the shear strength of removing the average residual strength $\left(\tau_{b r}=0.15 \mathrm{~N} / \mathrm{mm}^{2}\right)$ determined by Exp. I. The solid line in Fig. 11. is the punching shear strength of concrete calculated by formula (2), and the shear strength evaluation of the headed studs shown in the bold line is applied "Design Recommendations for Composite Constructions (Architectural Institute of Japan (AIJ))" [2010]. Further, this evaluation method is based on the shear strength evaluation of the headed studs proposed by Fisher et.al. [1971]. There is a variation in the test results for a value calculated by using AIJ. However, a value calculated by formula (2) is shown to be in good agreement with the test results. From the above results, regardless of the failure mode of headed studs, the shear strength of headed studs in the joints embedded the steel member in the reinforced concrete member should be estimated by superposing the average residual

bond strength across the steel-concrete interface.
However, to improve the proposed formula, more data of the pull-out tests for the joint type shown in Fig. 1 ( $c$ or b) is required.

\section{Conclusion}

The following remarks can be drawn from discussion presented above.

1) The experimental values of the average maximum and residual bond strength are $0.230-0.280$ and $0.15-0.18 \mathrm{~N} / \mathrm{mm}^{2}$, respectively.

2) When the distance of between the upper surface of the reinforced concrete member from the first layer for headed studs are small, the failure mode of the specimens is similar to a concrete-cone type failure.

3) In the case that the total number of headed studs or the hole provided to PBL is the same, the maximum load of the specimen with the parallel arrangement is larger than that of when shear connecters are vertically arranged.

4) The shear strength of headed studs in the joints embedded the steel member in the reinforced concrete member is estimated by superposing the average residual bond strength across the steel-concrete interface.

\section{References}

[1] Harugaze, Baba, Nishinura.Stress Transfer from Steel member to Reinforced Concrete Member (part6). Summaries of Technical Papers of Annual Meeting, Archtectural Institute of Japan 2001;Vol.C-I;1077-1078.

[2] Design Recommendations for Composite Constructions. Architectural Institute of Japan AIJ 2010

[3] Fisher, J.W. Shear Strenght of Stud Connectors in Lightweight and Normal weght concrete. A.I.S.C. 1971 